\title{
Heat resisting and water-soluble chocolate polyesters containing azomethine group
}

\author{
KEVSER TEMIZKAN, İSMET KAYA* \\ Çanakkale Onsekiz Mart University, Department of Chemistry, Polymer Synthesis and Analysis Laboratory, \\ 17020, Çanakkale, Turkey
}

\begin{abstract}
In this study, soluble in water poly(azomethine-ester)s (PAEs) were synthesized via elimination reactions of aromatic dihydroxy compounds containing imine bonding with terephthaloyl chloride. The structures of Schiff bases (SBs) and PAEs containing different aliphatic chains were confirmed by FT-IR, ${ }^{1} \mathrm{H}-\mathrm{NMR},{ }^{13} \mathrm{C}-\mathrm{NMR}$ and UV-Vis analyses. Physicochemical properties of the new polymers were characterized. Thermal properties of the compounds were investigated by TGA-DTA, DMA and DSC. According to TGA measurements, the starting degradation temperatures $\left(\mathrm{T}_{\mathrm{on}}\right)$ of $\mathrm{P}-1, \mathrm{P}-2, \mathrm{P}-3$, and $\mathrm{P}-4$ poly(azomethine-ester)s were found as $255^{\circ} \mathrm{C}, 232{ }^{\circ} \mathrm{C}, 22{ }^{\circ} \mathrm{C}$, and $221{ }^{\circ} \mathrm{C}$, respectively. The starting degradation temperatures of the poly(azomethine-ester)s were higher than their Schiff base compounds. According to dynamical mechanical analysis (DMA) measurements, glass transition temperature $\left(\mathrm{T}_{\mathrm{g}}\right)$ of P-1, P-2, P-3, and P-4 poly(azomethine-ester)s were found as $95^{\circ} \mathrm{C}$, $138{ }^{\circ} \mathrm{C}, 140{ }^{\circ} \mathrm{C}$, and $145^{\circ} \mathrm{C}$, respectively. The morphological and topographic properties of the PAEs containing azomethine linkage in the main chain were investigated by FE-SEM and AFM, respectively. The molecular mass distributions of PAEs were determined by gel permeation chromatography (GPC). Electrochemical $\left(\mathrm{E}_{\mathrm{g}}^{\prime}\right)$ and optical band gap $\left(\mathrm{E}_{\mathrm{g}}^{\mathrm{opt}}\right)$ values of the prepared SBs and PAEs were calculated from cyclic voltammetry $(\mathrm{CV})$ and $\mathrm{UV}$-Vis analyses. The electrochemical band gap $\left(\mathrm{E}_{\mathrm{g}}^{\prime}\right)$ values of P-1, P-2, P-3 and P-4 were found as $2.44 \mathrm{eV}, 2.41 \mathrm{eV}, 2.39 \mathrm{eV}$ and $2.39 \mathrm{eV}$, respectively, from the cyclic voltammetry.
\end{abstract}

Keywords: poly(azomethine-ester); Schiff base, water-soluble; electrochemical properties; thermal degradation; elimination reactions

\section{Introduction}

Water-soluble polymers are used in many fields including food, textiles, construction and pharmaceutical industries, coating technologies, dye industry, adhesives, and water cleaning [1-3]. Developments of nanotechnology, environmental engineering, biomedical engineering, information technologies and smart devices with biocompatible and environment-friendly properties resulted from extensive studies of these compounds [4-6]. Information technology created new applications for these materials such as electrically-sensitive or optical films. Synthetic water-soluble polymers have been designed with properties never realized before in natural polymers to meet the requirements of these novel applications. Architectural freedom places water-soluble polymers in a center of the fields of nanotechnology and smart materials [7].

*E-mail: kayaismet@hotmail.com
Polyazomethines are $\pi$ conjugated polymeric materials that possess good mechanical properties and high thermal stability, and exhibit the properties of liquid crystals. They have already been used in optoelectronic and nonlinear optical materials [8].

Polymers that contain imine and ester groups in main-chain demonstrate double-degradation properties both chemical and biological. Generally, the degradation rate of these polymers decreases when the number of imine groups in the polymeric chain increases. They are thermodynamically stable and maintain their molecular weight and mechanical strength in air. Still, the imine bonds easily hydrolyze, when they are exposed to water, breaking up the polymer chains into oligomers. After such water cracking, these oligomers are biodegraded into $\mathrm{CO}_{2}$ and water. Additionally, the imine bonds are restored by evaporation of water, leading to improvement of the molecular weight and the mechanical properties of the PAEs. 
The PAEs are considered to be a class of doubledegradable polymers, combining chemical and biological degradability features [9].

The main aim of the present study was to synthesize novel poly(azomethine-ester)s soluble in water via elimination reactions of aromatic dihydroxy and terephthaloyl chloride compounds. The structures of P-1, P-2, P-3 and $\mathrm{P}-4$ poly(azomethine-ester) compounds were confirmed by FT-IR, UV-Vis, ${ }^{1} \mathrm{H}$ - and ${ }^{13} \mathrm{C}-\mathrm{NMR}$. The characterizations of this poly(azomethine-ester)s were performed by TG-DTA, DSC, DMA, FESEM, AFM, CV and GPC. Thermal stabilities of SB-1, SB-2, SB-3 and SB-4 and P-1, P-2, $\mathrm{P}-3$ and P-4 poly(azomethine-ester)s were studied by TG-DTA. Electrochemical properties such as the HOMO, LUMO energy levels and electrochemical band gaps $\left(\mathrm{E}_{\mathrm{g}}^{\prime}\right)$ of all monomers and poly(azomethine-ester)s were calculated from oxidation and reduction onset values by cyclic voltammetry measurements. The optical band gaps $\left(\mathrm{E}_{\mathrm{g}}^{\mathrm{opt}}\right)$ of SB-1, SB-2, SB-3 and SB-4 and P-1, P-2, P-3 and P-4 poly(azmethine-ester)s were calculated from absorption edges of UV-Vis spectra.

\section{Experimental}

\subsection{Chemicals}

Ethylene diamine, 1,4-diaminobutane, 1,6diaminohexane, 1,8-diaminooctane were supplied by Fluka. 2-hydroxybenzaldehyde, terephthaloyl chloride, sodium carbonate $\left(\mathrm{Na}_{2} \mathrm{CO}_{3}\right)$, dimethylformamide (DMF), methanol $(\mathrm{MeOH})$, ethyl acetate, hexane, dimethyl sulfoxide (DMSO), tetrahydrofuran (THF), acetonitrile were purchased from Merck Chem., Co. (Germany).

\subsection{Synthesis of Schiff bases and their polyesters}

Schiff bases abbreviated as SBs were prepared by the condensation reaction of 2-hydroxybenzaldehyde $(0.02 \mathrm{~mol})$ with ethylenediamine (0.01 mol) (1,4-butanediamine, hexamethylenediamine, octamethylenediamine $(0.01 \mathrm{~mol}))$ in $60 \mathrm{~mL}$ of methanol, by boiling the mixture under reflux for $6 \mathrm{~h}$ (Fig. 1). The obtained SBs were filtered, recrystallized from acetonitrile and dried in vacuum desiccators $[9,10]$. The yields of SB-1, SB-2, SB-3 and SB-4 compounds were found as $73 \%, 74 \%, 74 \%$ and $76 \%$, respectively.

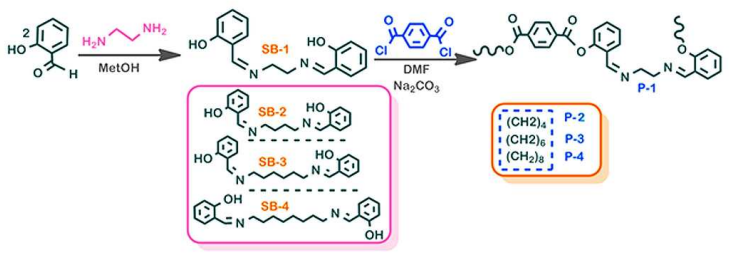

Fig. 1. Synthesis of Schiff base and poly(azomethineester)s.

Poly(azomethine-ester)s were synthesized by the condensation reaction of the obtained Schiff bases with terephthaloyl chloride. The polymers were abbreviated as P-1, P-2, P-3 and P-4. Synthesis procedures of the PAEs were as follows: SB-1 (0.04 mol) and dry DMF $(25 \mathrm{~mL})$ were charged into a $250 \mathrm{~mL}$ round-bottom flask. An amount of $0.02 \mathrm{~mol}$ of $\mathrm{Na}_{2} \mathrm{CO}_{3}$, dissolved in DMF $(5 \mathrm{~mL})$, was added to this mixture and heated $\left(60{ }^{\circ} \mathrm{C}, 1 \mathrm{~h}\right)$ with stirring under argon atmosphere. An amount of $0.02 \mathrm{~mol}$ of terephthaloyl chloride, dissolved in DMF $(30 \mathrm{~mL})$, was added to this mixture. The temperature increased to $150{ }^{\circ} \mathrm{C}$ and the reaction mixture was stirred under argon atmosphere for $5 \mathrm{~h}$ and left overnight for completion of the reaction. The reaction solution was poured into $200 \mathrm{~mL}$ of chloroform and the precipitated crude product was collected [11]. The obtained PAEs were washed with methanol $(25 \mathrm{~mL})$. The polymers were dried in a vacuum oven at $70{ }^{\circ} \mathrm{C}$ for $36 \mathrm{~h}$ [12]. The yields of P-1, P-2, P-3 and P-4 poly(azomethine-ester)s were found as $68 \%, 69 \%, 69 \%$ and $67 \%$, respectively.

\subsection{Characterization techniques}

Infrared spectra were measured by PerkinElmer Spectrum One FT-IR system and recorded for a solid sample in a powder form at room conditions using universal ATR sampling accessory within the wavelengths of $4000 \mathrm{~cm}^{-1}$ to $650 \mathrm{~cm}^{-1}$. 
UV-Vis spectra of Schiff bases and poly(azomethine-ester)s were measured in Analytik Jena Specord 210 Plus at $25{ }^{\circ} \mathrm{C}$ using DMF as a solvent. ${ }^{1} \mathrm{H}$ NMR and ${ }^{13} \mathrm{C}$ NMR spectra (JEOL ECX-400 II and 100.6 MHz) were obtained by $\mathrm{DMSO}_{\mathrm{d} 6}$ as a solvent at room temperature. The GPC analyses were performed using a Shimadzu $10 \mathrm{AVp}$ series HPLC-GPC system, calibrated with a mixture of polystyrene standards. The analyses were carried out by $\mathrm{DMF} / \mathrm{MeOH}(\mathrm{v} / \mathrm{v}, 4 / 1)$ as eluent at a flow rate of $0.4 \mathrm{~mL} / \mathrm{min}$ at room temperature. Polystyrene standards were used because they are similar in terms of aromaticity with bifunctional organic polymeric particles. Electrochemical properties of nanoparticles were explored with a $\mathrm{CHI}$ 660C Electrochemical Analyzer $(\mathrm{CH}$ Instruments, Texas, USA) in $0.1 \mathrm{~mol} \cdot \mathrm{L}^{-1}$ tetrabutylamonium hexafluorophosphate as supporting electrolyte. The voltammetric measurements were performed in a dry box under argon gas atmosphere at room temperature. A glassy carbon working electrode (GCE) and an Ag wire were used as reference electrodes. Platinum wire was used as a counter electrode. The highest occupied molecular orbital (HOMO) and lowest unoccupied molecular orbital (LUMO) energy levels were calculated from oxidation and reduction onset values [13]. The surface morphologies of the polyesters were determined by a JEOL JSM-7100F Schottky field emission scanning electron microscope. The TG/DTG-DTA thermograms were recorded using a PerkinElmer diamond thermal analysis in dynamic nitrogen atmosphere at a flow rate of $200 \mathrm{~mL} \cdot \mathrm{min}^{-1}$ from $293 \mathrm{~K}$ to $1273 \mathrm{~K}$. The heating rates were chosen as $10^{\circ} \mathrm{C} \cdot \mathrm{min}^{-1}$ and the sample mass ranged from $8 \mathrm{mg}$ to $10 \mathrm{mg}$. A platinum crucible was used as a sample container. DSC measurements were performed between $25^{\circ} \mathrm{C}$ and $450{ }^{\circ} \mathrm{C}$ (in $\mathrm{N}_{2}$, heating rate $10^{\circ} \mathrm{C} \cdot \mathrm{min}^{-1}$ ) using a PerkinElmer Pyris Sapphire DSC instrument. Topography and 3D images of the polymeric films were recorded by atomic force microscopy (AFM) Alpha 300 A (WITec, Ulm, Germany). Specified surface areas of the polymers were scanned angularly by a cantilever in non-contact mode (AC, $42 \mathrm{~N} / \mathrm{m}, 285 \mathrm{kHz}$ ). DMA tests were carried out by PerkinElmer Pyris Diamond DMA 115 V using a single cantilever in a bending mode at a frequency of $1 \mathrm{~Hz}$, a heating rate of $3{ }^{\circ} \mathrm{C} \cdot \mathrm{min}^{-1}$ and in the range of $20{ }^{\circ} \mathrm{C}$ to $350{ }^{\circ} \mathrm{C}$. The samples were prepared as follows: $0.5 \mathrm{~g}$ of polymer was placed into the titanium clamps (supplied from Triton Technology, Ltd., United Kingdom) and closed by bending the clamps at both sides.

\section{Results and discussion}

\subsection{Solubility}

All of the synthesized poly(azomethine-ester)s and their Schiff bases were found to be soluble in water, but insoluble in some non-polar solvents like benzene, hexane and toluene. PAEs were also insoluble in various organic solvents such as chloroform, tetrahydrofuran, dimethyl sulfoxide and dichloromethane. They only were partially soluble in DMF. The poly(azomethine-ester)s were insoluble in most of the organic solvents maybe due to the induction of flexibility via the spacer chain in the polymer backbone in addition to the inclusion of bent shaped aliphatic groups that are typical of poly(azomethine-ester)s and Schiff bases, which then make them more processable and feasible for various potential applications. Images of poly(azomethine-ester)s granules and their solubilities in waters are given in Fig. 2 and Fig. 3, respectively.

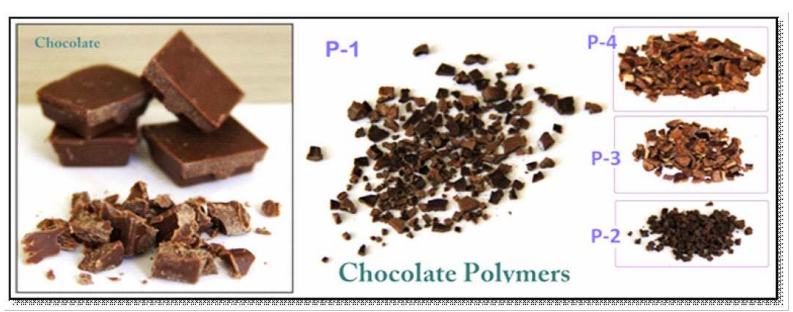

Fig. 2. Image of poly(azomethine-ester) granules.

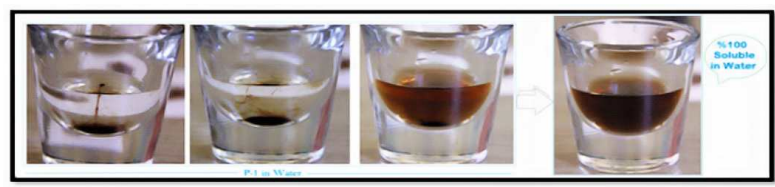

Fig. 3. Solubility process of P-1 in water. 


\subsection{Spectral characterization of the com- pounds}

The structures of the poly(azomethine-ester)s and Schiff bases were confirmed via FT-IR, ${ }^{1} \mathrm{H}$ and ${ }^{13} \mathrm{C}$ NMR spectroscopy. A new large band between $3280 \mathrm{~cm}^{-1}$ and $3200 \mathrm{~cm}^{-1}$ was found which proves and verifies the structure of SBs. Aliphatic stretch vibrations were observed in the range of $2912 \mathrm{~cm}^{-1}$ to $2900 \mathrm{~cm}^{-1}$. FT-IR spectra of all the SBs are quite similar to each other on account of structural similarities. Last four spectra of PAEs presented a strong band at around $1730 \mathrm{~cm}^{-1}$ after the polymerization, representing the functional group of $\mathrm{C}=\mathrm{O}$ ester, which confirmed the success of polymerization $[14,15]$ to form P-1, P-2, P-3 and $\mathrm{P}-4$, as illustrated in Fig. 4. In the first four spectra of SBs (Fig. 4), a strong peak was observed between $1665 \mathrm{~cm}^{-1}$ and $1636 \mathrm{~cm}^{-1}$ azomethine $(\mathrm{C}=\mathrm{N})$ stretching $[15,16]$. All homologous series of the polymers were found to give similar results.

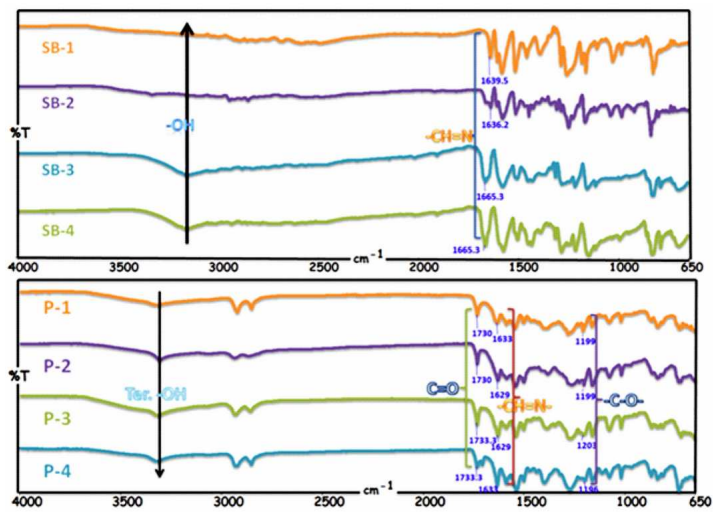

Fig. 4. FT-IR spectra of the SBs and PAEs.

The ${ }^{1} \mathrm{H}$ NMR spectra of SB-3 (Fig. 5) showed the occurrence of signals broadening and imine peak of this monomer were observed at $8.47 \mathrm{ppm}$. The proton decoupled ${ }^{13} \mathrm{C}$ NMR spectrum of SB-3 (Fig. 5) exhibited the expected peaks for each of the carbon atoms of the Schiff base in which the chemical shift of $\mathrm{C}=\mathrm{N}$ (imine) appeared at $165.64 \mathrm{ppm}$ and the chemical shift of $\mathrm{C}-\mathrm{OH}$ was found at $160.88 \mathrm{ppm}$ [17].

The aromatic and aliphatic proton signals in the ${ }^{1} \mathrm{H}$ NMR spectra of P-3 were observed at about $8.20 \mathrm{ppm}$ to $6.69 \mathrm{ppm}$ and $1.21 \mathrm{ppm}$ to $3.43 \mathrm{ppm}$.

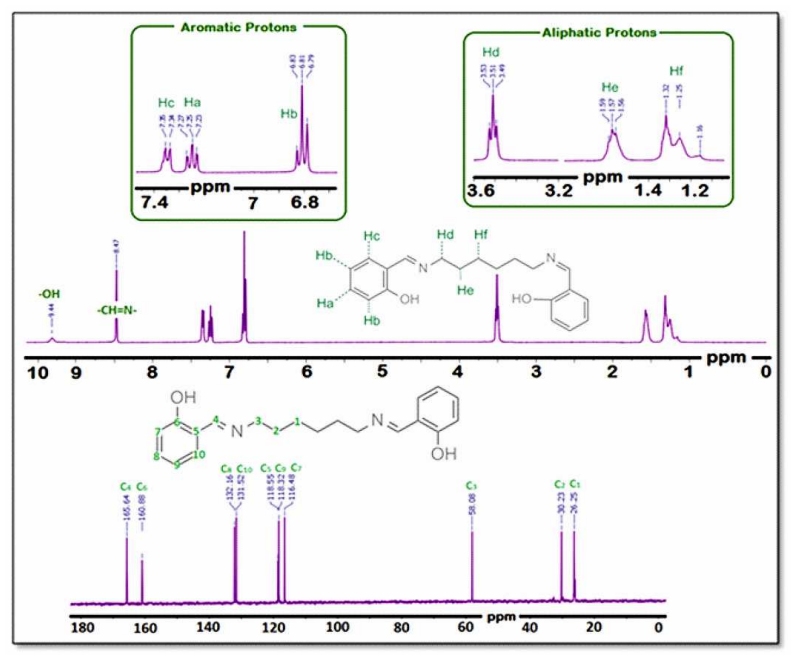

Fig. 5. ${ }^{1} \mathrm{H}$ and ${ }^{13} \mathrm{C}$ NMR spectra of SB-3.

Imine peak was observed at $8.56 \mathrm{ppm}$, while a small peak of terminal $-\mathrm{OH}$ at $10.06 \mathrm{ppm}$ (Fig. 6). According to, the ${ }^{13} \mathrm{C}$ NMR data of P-3, ester carbonyl and imine carbons were observed at 167.16 ppm to $166.09 \mathrm{ppm}$ and $165.64 \mathrm{ppm}$, respectively [18]. Aliphatic $-\mathrm{CH}_{3}$ signal of P-3 was seen between $28.88 \mathrm{ppm}$ and $58.84 \mathrm{ppm}$, while the other peaks of ipso aromatic carbons of the P-3: C6 and $\mathrm{C} 16$, in the range of $159.96 \mathrm{ppm}$ to $162.23 \mathrm{ppm}$, respectively. Aromatic carbons were also observed between $165.64 \mathrm{ppm}$ and $116.13 \mathrm{ppm}$ (Fig. 6). NMR analysis results confirmed the formation of poly(azomethine-ester)s and Schiff bases.

The molecular weights distributions of the resulting poly(azomethine-ester)s were determined by gel permeation chromatography (GPC). The number-average molecular weight $\left(\mathrm{M}_{\mathrm{n}}\right)$, the weight-average molecular weight $\left(\mathrm{M}_{\mathrm{w}}\right)$ and the polydispersity index (PDI) values of PAEs were calculated in DMF solution by polystyrene standards. The values of $M_{n}, M_{w}$ and PDI values of P-1 were determined as $11550 \mathrm{Da}, 15600 \mathrm{Da}$ and 1.35 , respectively.

To examine the electronic states of the polyesters, UV-Vis absorption and photoluminescence measurements were performed. Fig. 7 shows UV-Vis spectra of PAEs and SBs, and the obtained results are also summarized in Table 1. According to UV-Vis spectra of SBs, they show three 


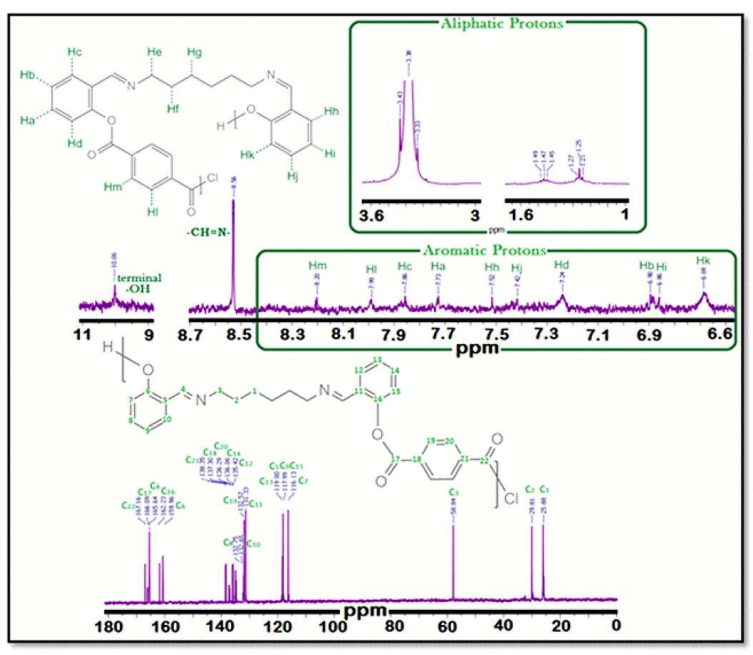

Fig. 6. ${ }^{1} \mathrm{H}$ and ${ }^{13} \mathrm{C}$ NMR spectra of P-3.

absorption bands. The first absorption band is observed between $280 \mathrm{~nm}$ and $290 \mathrm{~nm}$ due to $\pi \rightarrow \pi^{*}$ transition of benzene linkage. The second and third absorption bands are observed in the range $290 \mathrm{~nm}$ to $350 \mathrm{~nm}$ and $351 \mathrm{~nm}$ to $455 \mathrm{~nm}$ due to $\pi \rightarrow \pi^{*}$ and $n \rightarrow \pi^{*}$ transitions of azomethine linkage, respectively [18]. According to UV-Vis spectra of the PAEs, they show four absorption band. The first absorption band is observed between $280 \mathrm{~nm}$ and $320 \mathrm{~nm}$ due to $\pi \rightarrow \pi^{*}$ transition of benzene linkage. The second absorption bands are observed between $320 \mathrm{~nm}$ and $380 \mathrm{~nm}$ to $\pi \rightarrow \pi^{*}$ transition of ester linkage. The third and fourth absorption bands are observed in the range $380 \mathrm{~nm}$ to $500 \mathrm{~nm}$ and $500 \mathrm{~nm}$ to $710 \mathrm{~nm}$ due to $\pi \rightarrow \pi^{*}$ and $\mathrm{n} \rightarrow \pi^{*}$ transitions of azomethine linkage, respectively $[17,19]$.

\subsection{Electrochemical properties}

The electrochemical behavior of SBs and PAEs was investigated by cyclic voltammetry $(\mathrm{CV})$ with a three-electrode electrochemical cell. The highest occupied molecular orbital (HOMO), the lowest unoccupied molecular orbital (LUMO) and electrochemical band gap $\left(\mathrm{E}_{\mathrm{g}}^{\prime}\right)$ values of PAEs were calculated in order to understand electronic structures of the synthesized materials. The cyclic voltammograms of the Schiff bases and poly(azomethineester)s are given in Fig. 8. HOMO, LUMO and
Table 1. Optical band gaps, $\lambda_{\max }, \lambda_{\text {onset values of the }}$ Schiff bases and their poly(azomethine-ester)s.

\begin{tabular}{cccc}
\hline Compounds & $\lambda_{\max }[\mathrm{nm}]$ & $\lambda_{\text {onset }}[\mathrm{nm}]$ & $\mathrm{a}\left(\mathrm{E}_{\mathrm{g}}^{\mathrm{opt}}\right)[\mathrm{eV}]$ \\
\hline \hline SB-1 & $257,315,412$ & 444 & 2.80 \\
SB-2 & $255,314,402$ & 448 & 2.77 \\
SB-3 & $253,317,400$ & 451 & 2.75 \\
SB-4 & $254,313,404$ & 455 & 2.73 \\
P-1 & $320,405,548,687$ & 702 & 1.76 \\
P-2 & $301,347,415,599$ & 702 & 1.76 \\
P-3 & $280,342,480,680$ & 703 & 1.77 \\
P-4 & $280,347,487,682$ & 705 & 1.76 \\
\hline
\end{tabular}

${ }^{\mathrm{a}}$ Optical band gap

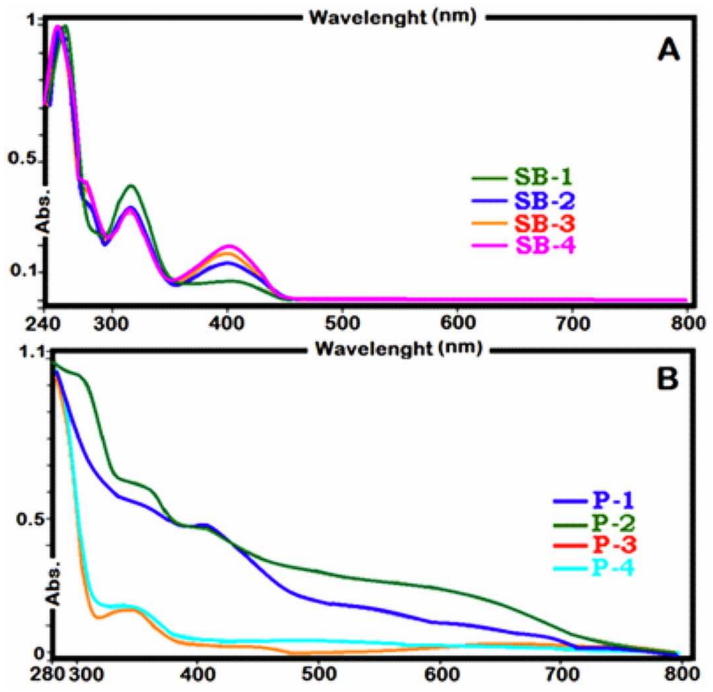

Fig. 7. Absorption spectra of SBs and PAEs.

$\mathrm{E}_{\mathrm{g}}^{\prime}$ values of the Schiff bases and poly(azomethineester)s were calculated by using equation 1 , equation 2 and equation 3, respectively, as in literature $[17,19]$ and the obtained results are summarized in Table 2.

$$
\begin{gathered}
E_{\text {Номо }}=-\left(4.39+E_{\text {ox }}\right) \\
E_{L U M O}=-\left(4.39+E_{\text {red }}\right) \\
E_{g}^{\prime}=E_{L U M O}-E_{\text {HOMO }}
\end{gathered}
$$

The onset oxidation potential $\left(\mathrm{E}_{\mathrm{ox}}\right)$ values of the Schiff bases and poly(azomethine-ester)s were 
Table 2. Electrochemical data of the Schiff bases and their poly(azomethine-ester)s.

\begin{tabular}{cccccc}
\hline Compounds & $\mathrm{E}_{\text {ox. }}[\mathrm{V}]$ & ${ }^{\mathrm{a}} \mathrm{HOMO}[\mathrm{eV}]$ & $\mathrm{E}_{\text {red. }}[\mathrm{V}]$ & ${ }^{\mathrm{b}}$ LUMO $[\mathrm{eV}]$ & ${ }^{\mathrm{c}} \mathrm{E}_{\mathrm{g}}^{\prime}[\mathrm{eV}]$ \\
\hline \hline SB-1 & 1.3261 & -5.7161 & -1.2610 & -3.1290 & 2.59 \\
SB-2 & 1.3636 & -5.7536 & -1.2727 & -3.1173 & 2.64 \\
SB-3 & 1.3513 & -5.7413 & -1.2604 & -3.1296 & 2.61 \\
SB-4 & 1.2949 & -5.6849 & -1.2604 & -3.1296 & 2.56 \\
P-1 & 1.2698 & -5.6598 & -1.1729 & -3.2171 & 2.44 \\
P-2 & 1.0449 & -5.4349 & -1.3726 & -3.0174 & 2.41 \\
P-3 & 1.2450 & -5.6350 & -1.1477 & -3.2423 & 2.39 \\
P-4 & 1.2821 & -5.6721 & -1.1102 & -3.2798 & 2.39 \\
\hline
\end{tabular}

${ }^{\text {a Highest occupied molecular orbital }}$

${ }^{\mathrm{b}}$ Lowest unoccupied molecular orbital

${ }^{\mathrm{c}}$ Electrochemical band gap.
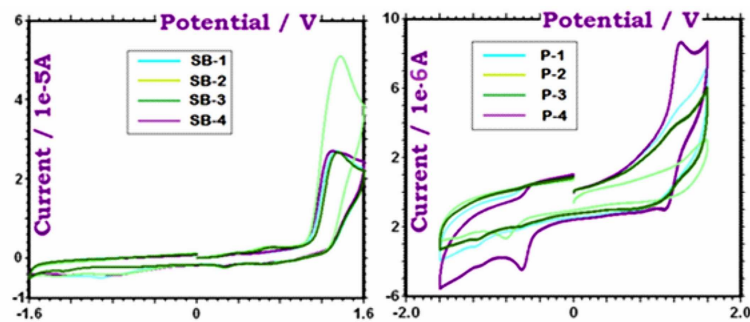

Fig. 8. Cyclic voltammograms of SBs and PAEs (scan rate: $-0.2 \mathrm{~V} / \mathrm{s}$ to $0.2 \mathrm{~V} / \mathrm{s})$.

in the range $1.2949 \mathrm{~V}$ to $1.3636 \mathrm{~V}$ and $1.0449 \mathrm{~V}$ to $1.2821 \mathrm{~V}$, respectively. The HOMO energy levels of the Schiff bases and poly(azomethine-ester)s were determined between $-5.69 \mathrm{eV}$ to $-5.75 \mathrm{eV}$ and $-5.44 \mathrm{eV}$ to $-5.67 \mathrm{eV}$, respectively. Similarly, the onset reduction potential $\left(\mathrm{E}_{\mathrm{red}}\right)$ values of the Schiff bases and poly(azomethine-ester)s were between $-1.2604 \mathrm{~V}$ and $-1.2727 \mathrm{~V}$ and $-1.1102 \mathrm{~V}$ and $-1.3726 \mathrm{~V}$, respectively. The LUMO energy level of the Schiff bases and poly(azomethineester)s were calculated between $-3.12 \mathrm{eV}$ and $-3.13 \mathrm{eV}$ and $-3.02 \mathrm{eV}$ to $-3.28 \mathrm{eV}$, respectively. The electrochemical band gaps $\left(\mathrm{E}_{\mathrm{g}}^{\prime}\right)$ of SB-1, SB-2, SB-3 and SB-4 were calculated as $2.59 \mathrm{eV}, 2.64 \mathrm{eV}$, $2.61 \mathrm{eV}$, and $2.56 \mathrm{eV}$, respectively. The electrochemical band gap $\left(\mathrm{E}_{\mathrm{g}}^{\prime}\right)$ of poly(azomethine-ester)s were calculated according to the literature [20] and equation 3 . The values of P-1, P-2, P-3 and $\mathrm{P}-4$ were determined as $2.44 \mathrm{eV}, 2.41 \mathrm{eV}, 2.39 \mathrm{eV}$ and $2.39 \mathrm{eV}$, respectively. According to these results, the poly(azomethine-ester)s had quite lowelectrochemical band gap values.

\subsection{Thermal properties}

The thermal properties of PAEs were investigated by using TGA-DTA and DSC techniques to determine the thermal degradation pattern and glass transition temperature. TGA-DTA curves of the poly(azomethine-ester)s are shown in Fig. 9 and thermal analysis results for monomers and poly(azomethine-ester)s are summarized in Table 3.

As can be seen in Fig. 9, P-1, P-2 and P-3 decomposed in three steps whereas $\mathrm{P}-4$ decomposed in two steps. According to TGA-DTA thermograms, the onset temperatures of SB-1, SB-2, SB-3 and SB-4 were found as $150{ }^{\circ} \mathrm{C}, 138{ }^{\circ} \mathrm{C}, 112{ }^{\circ} \mathrm{C}$, and $126^{\circ} \mathrm{C}$, respectively. According to TGA curves of the poly(azomethine-ester)s, the onset temperatures of P-1, P-2, P-3 and P-4 were found as $255^{\circ} \mathrm{C}$, $232{ }^{\circ} \mathrm{C}, 222{ }^{\circ} \mathrm{C}$, and $221^{\circ} \mathrm{C}$, respectively. The onset temperatures $\left(\mathrm{T}_{\mathrm{on}}\right)$ of the poly(azomethine-ester)s were found higher than for Schiff base compounds. The $\mathrm{T}_{\text {on }}$ values of SB-1 and P-1 were found higher than other Schiff bases and polymers. Thermal stabilities of these compounds are very good, because the aliphatic bridge is the shortest between imine bonding in SB-1 and P-1 compounds. The \% chars of P-1, P-2, P-3, and P-4 were found as $13 \%, 12 \%$, $7 \%$, and $4 \%$, respectively, at $1000{ }^{\circ} \mathrm{C}$. Both onset 
Table 3. Thermal degradation data of water-soluble SBs and PAEs.

\begin{tabular}{cccccccccc}
\hline \multicolumn{2}{c}{ Compounds } & SB-1 & SB-2 & SB-3 & SB-4 & P-1 & P-2 & P-3 & P-4 \\
\hline \hline \multirow{5}{*}{ The first step } & ${ }^{\mathrm{a}} \mathrm{T}_{\text {on }}$ & 150 & 138 & 112 & 126 & 255 & 232 & 222 & 221 \\
& ${ }^{\mathrm{b}} \mathrm{T}_{\text {max }}$ & 160 & 150 & 138 & 179 & 433 & 263 & 418 & 438 \\
& ${ }^{\mathrm{c}} \mathrm{T}_{\text {end }}$ & 208 & 218 & 227 & 253 & 495 & 350 & 477 & 540 \\
& ${ }^{\mathrm{d} \%}$ & 47 & 47 & 53 & 45 & 31 & 15 & 35 & 30 \\
\hline \multirow{5}{*}{ The second step } & ${ }^{\mathrm{e}} \mathrm{T}_{\text {str. }}$ & 208 & 218 & 227 & 253 & 495 & 350 & 477 & 540 \\
& $\mathrm{~T}_{\max }$ & 301 & 313 & 318 & 318 & 575 & 552 & 850 & 855 \\
& $\mathrm{~T}_{\text {end }}$ & 1000 & 1000 & 1000 & 377 & 725 & 800 & 913 & 1000 \\
& $\%$ & 35 & 45 & 43 & 32 & 21 & 47 & 48 & 63 \\
\hline \multirow{5}{*}{ The third step } & $\mathrm{T}_{\text {str. }}$ & - & - & - & 377 & 725 & 800 & 913 & - \\
& $\mathrm{T}_{\max }$ & - & - & - & 439 & 949 & 977 & 972 & - \\
& $\mathrm{T}_{\text {end }}$ & - & - & - & 1000 & 1000 & 1000 & 1000 & - \\
& $\%$ & - & - & - & 17 & 35 & 26 & 13 & - \\
\hline \multicolumn{2}{c}{${ }^{\mathrm{f}} \mathrm{T}_{20}$} & 145 & 150 & 131 & 162 & 350 & 457 & 460 & 411 \\
\hline \multicolumn{2}{c}{${ }^{\mathrm{g}} \mathrm{T}_{50}$} & 244 & 247 & 196 & 279 & 714 & 620 & 817 & 858 \\
\hline${ }^{\mathrm{h}}$ Char [\%] & 15 & 8 & 4 & 6 & 13 & 12 & 4 & 7 \\
\hline
\end{tabular}

${ }^{a}$ The onset temperature

${ }^{\mathrm{b}}$ Maximum weight loss temperature

${ }^{\mathrm{c}}$ Thermal degradation finishing temperature

${ }^{\mathrm{d}}$ Weight loss at the steps

${ }^{\mathrm{e}}$ Thermal degradation starting temperature

$\mathrm{f}_{20} \%$ weight loss

$\mathrm{g}_{50} \%$ weight loss

${ }^{\mathrm{h}} \mathrm{Char}$ at $1000{ }^{\circ} \mathrm{C}$

temperature and $\%$ char values at $1000{ }^{\circ} \mathrm{C}$ of $\mathrm{P}-1$ were higher than for other poly(azomethine-ester)s because P-1 poly(azomethine-ester) had the shortest chain. $\mathrm{T}_{\max }$ values of SB-1, SB-2, SB-3 and SB4 and P-1, P-2, P-3 and P-4 were found as $160{ }^{\circ} \mathrm{C}$, $150{ }^{\circ} \mathrm{C}, 138{ }^{\circ} \mathrm{C}$ and $179{ }^{\circ} \mathrm{C}$ and $433{ }^{\circ} \mathrm{C}, 263{ }^{\circ} \mathrm{C}$, $418{ }^{\circ} \mathrm{C}$ and $438{ }^{\circ} \mathrm{C}$, respectively. Also, the high values of $\mathrm{T}_{\max }$ of the poly(azomethine-ester)s are probably related to their molecular weights.

DSC and DMA curves of the poly(azomethineester)s are shown in Fig. 10 and Fig. 11, respectively. According to DSC measurements, the glass transition temperatures $\left(\mathrm{T}_{\mathrm{g}}\right)$ of $\mathrm{P}-1, \mathrm{P}-2$, $\mathrm{P}-3$, and P-4 were found as $140{ }^{\circ} \mathrm{C}, 145{ }^{\circ} \mathrm{C}$, $149{ }^{\circ} \mathrm{C}$, and $155{ }^{\circ} \mathrm{C}$, respectively. According to these results, the highest $\mathrm{T}_{\mathrm{g}}$ value was found for P-4 poly(azomethine-ester). Also, the $\Delta \mathrm{Cp}$ values of P-1, P-2, P-3, and P-4 were calculated from DSC curves as $0.124 \mathrm{~J} / \mathrm{g} \cdot \mathrm{K}, 0.140 \mathrm{~J} / \mathrm{g} \cdot \mathrm{K}, 0.148 \mathrm{~J} / \mathrm{g} \cdot \mathrm{K}$, and $0.150 \mathrm{~J} / \mathrm{g} \cdot \mathrm{K}$, respectively.

Dynamic mechanical analysis (DMA) of the polymers was carried out using single cantilever bending mode. Storage modulus (E'), loss modulus $\left(E^{\prime \prime}\right)$, and tangent delta $(\tan \delta)$ were measured as the functions of the sample temperature [21]. DMA analyses of PAEs were carried out as a function of temperature in the range $20{ }^{\circ} \mathrm{C}$ to $350{ }^{\circ} \mathrm{C}$. Tan $\delta$ curves of the crosslinked PAEs are shown in Fig. 11. The glass transition temperature $\left(\mathrm{T}_{\mathrm{g}}\right)$ of the poly(azomethine-ester)s were calculated from the maximum value in the $\tan \delta$ curve. The glass transition temperature $\left(\mathrm{T}_{\mathrm{g}}\right)$ values of $\mathrm{P}-1, \mathrm{P}-2$, $\mathrm{P}-3$, and P-4 were determined as $95{ }^{\circ} \mathrm{C}, 138{ }^{\circ} \mathrm{C}$, $140{ }^{\circ} \mathrm{C}$, and $145^{\circ} \mathrm{C}$, respectively. The $\mathrm{T}_{\mathrm{g}}$ values of the PAEs raised with increasing the chain length of poly(azomethine-ester)s. When compared 


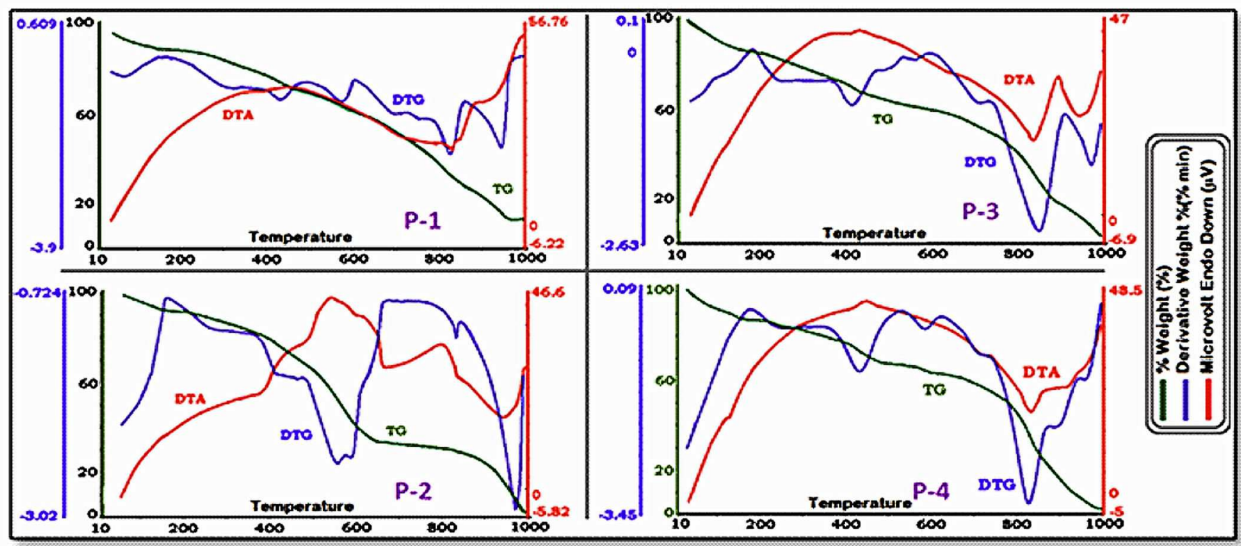

Fig. 9. TG, DTG and DTA curves of the synthesized PAEs.

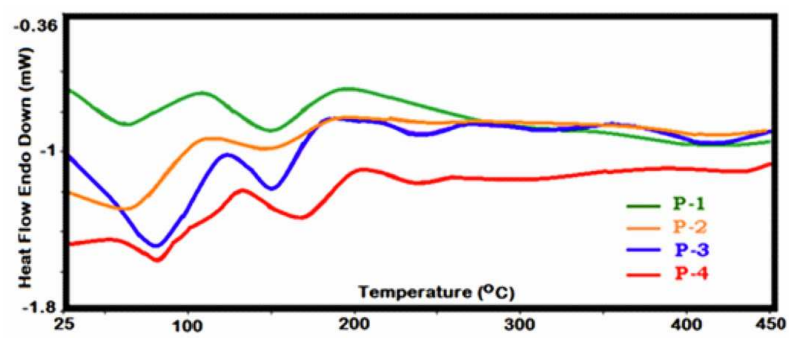

Fig. 10. DSC curves of the synthesized PAEs.

to glass-transition temperature obtained from DMA and DSC, $T_{g}$ values of poly(azomethineester)s are almost the same and the slight differences result from the different nature of these two methods. As it is known, DMA measures the change in the mechanical response of the poly(azomethine-ester) chains.

\subsection{Morphological properties}

AFM was used in order to evaluate the evolution of topography and the surface roughness of the poly(azomethine-ester)s (Fig. 12). Fig. 13 shows the 3D, topography and phase images of $\mathrm{P}-1$ sample. Root mean square roughness values $(\mathrm{Sq})$ for the polymers P1, P2, P3 and P4 are $6.8 \mathrm{~nm}$, $7.5 \mathrm{~nm}, 7.3 \mathrm{~nm}$ and $6.5 \mathrm{~nm}$, respectively. According to AFM images of the poly(azomethine-ester)s, the surfaces of these poly(azomethine-ester)s seem to be dispersed and inhomogeneous, having partly spherical shapes [22, 23].
FE-SEM technique was used to investigate surface morphology of the polyesters. Fig. 14 shows FE-SEM photographs of P-1, P-2, P-3 and P-4 with different particle sizes. According to FE-SEM images, the polyesters have a highly notched, indented and roughened surface [21, 24]. From the AFM and FE-SEM images it is seen that all the polymers have similar surfaces.

\section{Conclusions}

Poly(azomethine-ester)s soluble in water were successfully synthesized from Schiff bases synthesis process. The chemical structures of monomers and polymers were confirmed by ${ }^{1} \mathrm{H}$ NMR, ${ }^{13} \mathrm{C}$ NMR and FT-IR, UV-Vis spectroscopy. According to the thermal analysis results, the onset temperature of $\mathrm{P}-1$ was higher than of the other poly(azomethine-ester)s because the chain length of P-1 was shorter than of the other poly(azomethine-ester)s. The results from thermogravimetric analysis revealed that thermal stability of P-1, P-2, P-3 and P-4 species gradually decreased. The inventions described in this article seem to be particularly important from a commercial point of view to meet the strict requirements for several potential applications of such poly(azomethine-ester) species in structural materials. The HOMO, LUMO energy levels and electrochemical band gaps $\left(\mathrm{E}_{\mathrm{g}}^{\prime}\right)$ of the monomers and poly(azomethine-ester)s were calculated from 

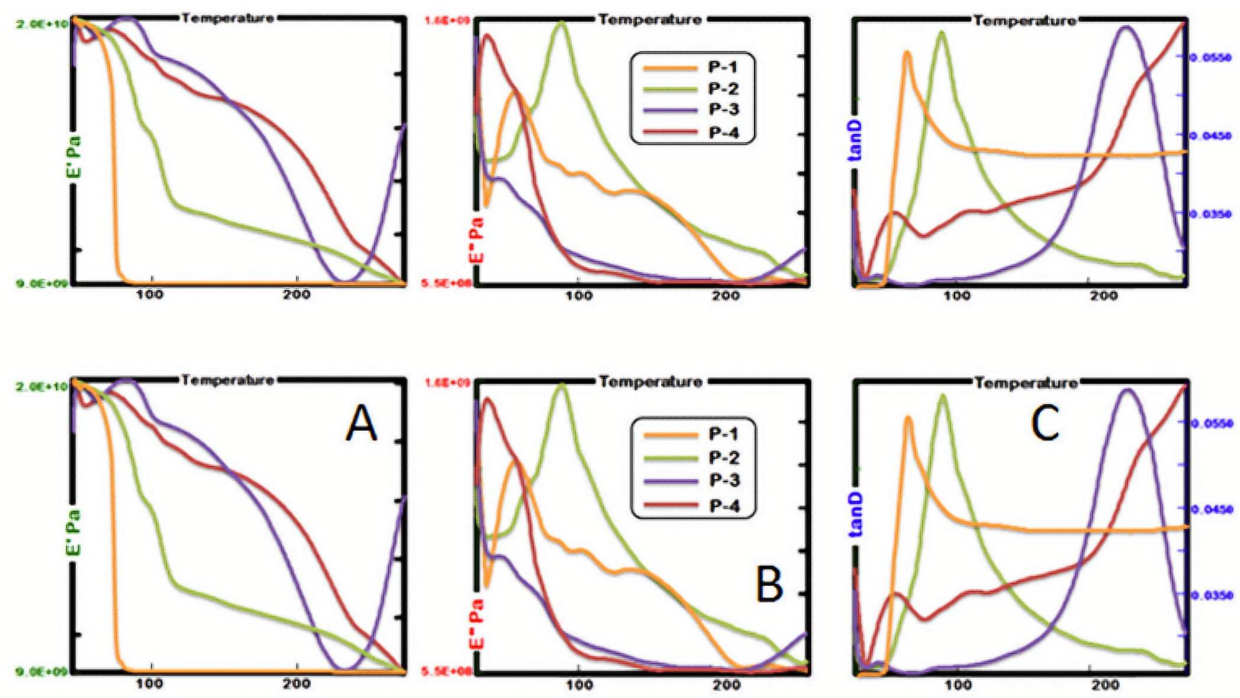

Fig. 11. Graphs of $E^{\prime}(A), E^{\prime \prime}(B)$ and $\tan \delta(C)$ moduli versus temperature for PAEs.

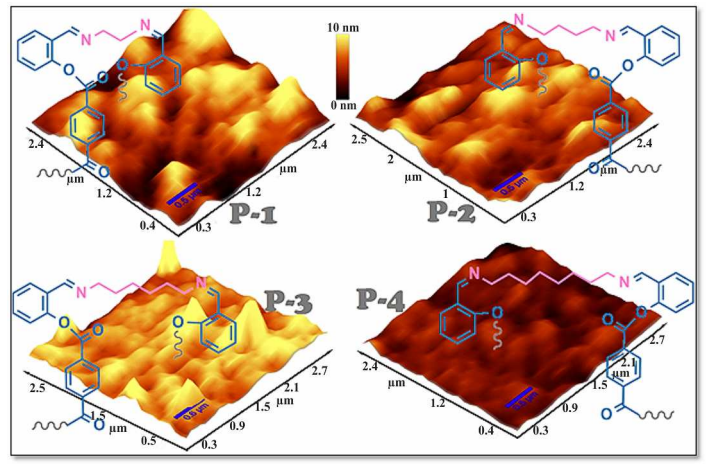

Fig. 12. AFM images of P-1, P-2, P-3 and P-4, respectively.

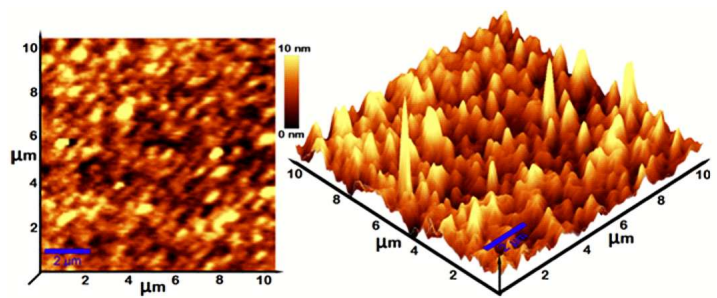

Fig. 13. Surface topography and 3D image of P-1 sample.

oxidation and reduction onset values by cyclic voltammetry measurements. Both electrochemical band gaps $\left(\mathrm{E}_{\mathrm{g}}^{\prime}\right)$ and optical band gap $\left(\mathrm{E}_{\mathrm{g}}^{\mathrm{opt}}\right)$ values of poly(azomethine-ester)s were found less than

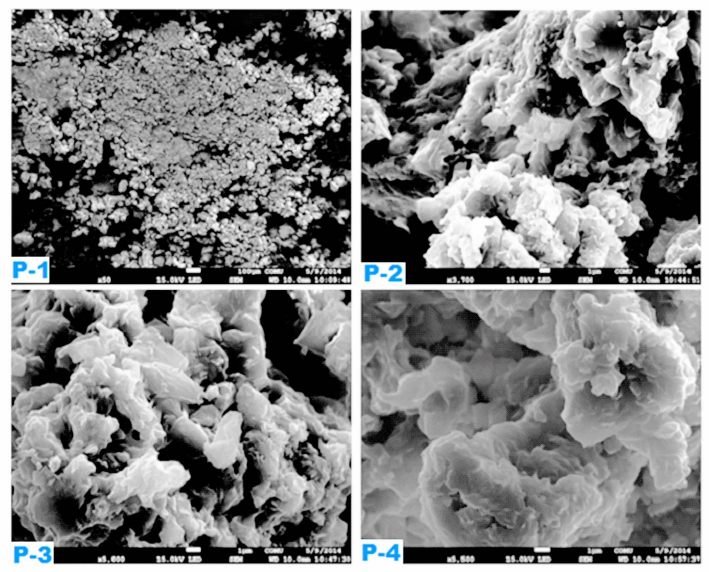

Fig. 14. FE-SEM images of poly(azomethine-ester)s.

those of their Schiff bases compounds. Therefore, the poly(azomethine-ester)s can be used for optical and photovoltaic applications.

\section{References}

[1] LeE H.W., Cho H.J., Yim J.H., KIM J.M., SoHN J.M., Yoo K.S., KIM S.S., JEON J.K., PARK Y.K., J. Ind. Eng. Chem., 17 (2011), 504.

[2] Kim J., Wainaina J., Na J.S., J. Ind. Eng. Chem., 17 (2011), 681.

[3] Khan M.M.A., Rafiuddin I., J. Ind. Eng. Chem., 19 (2013), 1365.

[4] Rhi W.Y., Kim H.M., Kyeong S., Kanga Y.L., KIm D.H., KANG H., JeONG C., Kim D.E., LEE Y.S., Jun B.H., J. Ind. Eng. Chem., 20 (2014), 2646. 
[5] Chang Y.W., Shin G., J. Ind. Eng. Chem., 17 (2011), 730.

[6] You D., Liang H., Mai W., Zeng R., Tu M., Zhao J.H., J. Ind. Eng. Chem., 13 (2013), 1587.

[7] Halake K., Birajdar M., Kim B.S., Bae H., Lee C.C., KIM Y.J., KIM S., KIM H.J., Ahn S., An S.Y., LEE J., J. Ind. Eng. Chem., 20 (2014), 3913.

[8] Kovalev D.S., Kostamin S.V., Mustea V., Cozan V., Bronnikov S.V., Phys. Solid State, 57 (2015), 1673.

[9] Fukuda K., Shimoda M., Sukegawa M., NoBORI T., LEHN J.M., Green Chem., 14 (2012), 2907.

[10] AfZal S., Gul A., AKhter Z., J. Inorg. Organomet. P., 24 (2014), 321.

[11] Kaya İ., Temizkan K., Aydin A., Mater. Sci. Eng. $B-A d v ., 178$ (2013), 863.

[12] KobZAR Y.L., TKACHENKO I.M., BLIZNYUK V.N., ShEKERA O.V., TURIV T.M., SOROKA P.V., NaZarenjo V.G., Shevchenko V.V., Des. Monomers Polym., 19 (2016), 1.

[13] KAYA İ., TEMIZKAN K., AYDIN A., J. Electroanal. Chem., 708 (2013), 54.

[14] Aly K.I., Hammam A.S., Radwan S.M., AbdelRahman M.A., J. Basic Appl. Sci., 11 (2011), 15.

[15] Malathy N., Singh D.R., Int. J. Chem. Res., (2012) 1.

[16] Avci A., Temizkan K., Kaya I., Polym. Bull., 72 (2015), 2871.
[17] Lim W.L., Oo C.W., Choo Y.S.L., Looi S.T., Polymer, 71 (2015), 15.

[18] Kaya İ., Kilavuz E., J Flouresc, 25 (2015), 663.

[19] Petrus M.L., BouWer R.K.M., Lafont U., Athanasopoulos S., Greenham N.C., DingeMANS T.J., J. Mater. Chem. A, 2 (2014), 9474.

[20] Petrus M.L., Bouwer R.K.M., LAFont U., MurThy D.H.K., KIST R.J.P., BOHM M.L., Olivier Y., SAVEniJe T.J., Siebbeles L.D.A., Greenhamd N.C., Dingemans T., J. Polym. Chem., 4 (2013), 4182.

[21] Avci A., Kamaci M., KaYa İ., Yildirim M., Mater. Chem. Phys., 163 (2015), 301.

[22] Palewicz M., Iwan A., Doskocz J., Strek W., Sek D., KaczmarczyK B., Mazurek B., Polym. Bull., 66 (2011), 65.

[23] RaCles C., Musteata V.E., Bele A., Dasalu M., Tugui C., Matricala A.L., RSC Adv., 5 (2015) 102599.

[24] Ravikumar L., Kalaivani S., Vidhyadevi T., Murugasen A., Kirupha S.D., Sivanesan S., Open J. Polym. Chem., 4 (2014), 1.

Received 2016-06-13

Accepted 2016-12-23 